\title{
Injection technology for sustainable environmental protection in the petroleum industry
}

\author{
B. Muvrin, Z. Kristafor, K. Simon, L. Maurovic \\ \& D. Karasalihovic \\ University of Zagreb, \\ Faculty of Mining, Geology and Petroleum Engineering, \\ Department of Petroleum Engineering, Croatia
}

\begin{abstract}
Since the petroleum industry is considered to be one of the main environmental polluters, increased attention is put on environmental protection during petroleum activities. During exploration, well stimulation and oil and gas production a certain amount of waste is produced. By using injection technology petroleum industry waste is injected into suitable underground geological formations, from where it originated and it is safely removed from the human biosphere. With the injection technology the liquid, solid and gaseous wastes are deposited simultaneously and safely into the selected formation. Compared to the injection technology, surface disposal of petroleum industry waste is much more expensive and more environmentally intensive. For the last two years the same technology has also been used in Croatia. At this moment, petroleum industry waste in Croatia is injected at just one oil field, but there are several projects that consider wells and geological structures suitable for disposal of this kind of waste. With the negative publicity regarding environmental impact in the past, and considering the new set of environmental laws and standards, the waste injection technology could be the solution for the petroleum industry on how to achieve sustainable waste management and diminish its impact on environmental balance that is predicted to be even greater. Furthermore, implementation of injection technology could also be the solution for the greenhouse gas problem.

Keywords: petroleum industry waste, injection technology, geological formation, $\mathrm{CO}_{2}$ sequestration.
\end{abstract}




\section{Introduction}

In last few decades more strict and resolute regulations regarding environmental protection have been posed to all energy related industries among which the petroleum industry is considered to be one of the main polluters. All this led to significantly increased attention surrounding environmental aspects in petroleum companies and to the fact that environmental considerations have attained a central position in the formulation of petroleum and energy companies's policy. Principles of environmental protection have successfully integrated into all segments of upstream operational procedures and activities, from exploration work, through drilling operations, field development, production of oil or natural gas and ending by field abandonment.

One of the emerging problems of petroleum companies, due to ever more strict environmental protection standards and laws, in last few decades is the problem of management of waste generated during exploration, drilling, production and refining activities. Most of all petroleum companies have developed waste management systems, which are more or less based on re-use, recycling, reduction and disposal of waste throughout every stage of operations. Many aspects of waste management are covered by regulations at national, regional and international levels. Regulatory requirements are usually embodied in licenses granted for specific operations. Due to mentioned environmental standards, safe disposal of waste, along with the limitation of world oil and gas resources, its disproportional global distribution and costs of production, has become one of the limiting factors and its impact on the future development of petroleum industry is predicted to be even greater.

\section{Petroleum industry waste}

Drilling during oil and natural gas exploration and production can produce considerable quantities of rock cuttings coated with residual amounts of drilling mud, which is lubricating fluid that, among other functions, prevents well bore collapse while drilling and transports drilled cuttings to the surface. Drilling mud is a complex mixture containing a number of additives which can be either water-based or oil-based. The drilling mud is considered to be primary technological waste from petroleum industry and, as opposed to secondary fluids, does not represent a big environmental problem. The bigger problem lies in the secondary fluids which include inorganic and organic acids, cellulose and oil gels, cement slurry, technological wastewater and salt solutions that cannot be used again, but should be neutralized with a proper neutralizer like lime, limestone or dolomite, and deposited in the environmentally friendly manner. Also, waste like brine, sand, $\mathrm{CO}_{2}$, reservoir and process facilities residua, oily water, paraffin etc., is generated during oil and natural gas production.

According to international standards technological waste from petroleum industry generated during exploration, drilling, production, refining and distribution activities can be, considering its generation site, divided into several groups as shown in table 1. 
Table 1: $\quad$ Types of petroleum industry technological waste.

\begin{tabular}{|c|c|}
\hline Waste & Content and physical and chemical characteristics \\
\hline $\begin{array}{c}\text { Brine produced } \\
\text { during hydrocarbon } \\
\text { production }\end{array}$ & $\begin{array}{c}\text { High content of chlorides, oil in traces, small size } \\
\text { particles of clay, other dissolved salts }\end{array}$ \\
\hline $\begin{array}{c}\text { Sand produced } \\
\text { during hydrocarbon } \\
\text { production }\end{array}$ & $\begin{array}{c}\text { Small to middle size granulated sand produced along } \\
\text { with heavy oil, }>85 \% \mathrm{Si}_{2}, \text { possible high content of } \\
\text { chlorides, } 4-5 \% \mathrm{wg} \text {. oil residua on sand particles }\end{array}$ \\
\hline Waste mud & $\begin{array}{c}\text { Rock cuttings, chlorides, sand, clay, water, chemicals, } \\
8 \% \text { of oil in emulsion, high pH, }\end{array}$ \\
\hline $\begin{array}{c}\text { Slime from storage } \\
\text { tank bottom, stable } \\
\text { emulsions }\end{array}$ & $\begin{array}{c}\text { Slime form separator tanks, chlorides, clay, brine, } \\
\text { asphaltens, variable oil content from } 30-50 \% \text { stabile } \\
\text { emulsion }\end{array}$ \\
\hline Slime & $\begin{array}{c}\text { Waste water, oil with particles of sand and clay, soil } \\
\text { polluted with oil (surface oil spills), chlorides, cycle } \\
\text { hydrocarbons }\end{array}$ \\
\hline
\end{tabular}

The amount of the waste produced during exploration and production activities depends on range of exploration and reservoir engineering activities, workover operations, production conditions and formation characteristics.

As hydrocarbon reservoirs are developed, water, which co-exists with oil and natural gas in the reservoirs, is brought to the surface. In oil fields in particular, quantities of produced water increase as reservoirs are depleted. In some cases, eventually more water is produced than oil. Since water production directly affected the profit of oil companies it was the first waste problem that was addressed and solved. The solution for water production was the development of injection technology which was introduced by petroleum industry only several decades after the beginning of commercial petroleum production. By the injection of water, today commonly known as the secondary recovery method of hydrocarbon production, into the hydrocarbon reservoir the production of hydrocarbons is enhanced and at the same time the problem of water as technological waste is solved.

With time, pressurized with waste problems, petroleum industry has improved the injection technology to the point where it can be used, not only for the water injection, but also for the injection of other types of waste. The petroleum industry waste injection technology is nowadays commonly implemented by most of the large world oil companies with approval and under the supervision of authorized state institutions.

The US Environmental Protection Agency (EPA) was one of the first regulatory organizations that set standards and rules for underground injection under Underground Injection Control Program. According to EPA injection activities are grouped into five classes. Class I includes injection of hazardous and non-hazardous fluids (industrial and municipal wastes) into geological formations beneath the lowest underground source of drinking water. Because Class I includes injection of hazardous waste, Class I wells are the most strictly regulated. Class II includes injection of fluids produced during oil and gas production. Class III encompasses injection of fluids associated with mineral 
mining activities. Injection of hazardous or radioactive waste into or above underground sources of drinking water is included in Class IV. Class V includes all underground injection not included in Classes I-IV [4-6].

\section{Petroleum waste injection technology}

The injection of different kind of petroleum industry waste is done using specially selected and registered wells. Wells, commonly used for waste injection, are negative wildcat wells, former production wells or injection wells, which are equipped especially for the injection purposes. Wells are located in areas where the waste is originally generated due to costs reduction of temporary deposition and transport. By injection technology, liquid, solid and gaseous waste can be simultaneously and safely deposited into the selected geological formation. Waste injection involves processing solid materials, produced during exploration, production and workover activities, to particles of suitable size and blending them with a fluid to make the slurry that can be injected into selected geological formations. Injection of slurry can be continuous or as a series of smaller volume cycles. Injection of waste can be conducted continuously for a few weeks, even months, after which follows non-injection period with pressure measurements. This period should be as long as to allow total dispersion of pressure and repeated estimation of reservoir parameters. During the period of injection, the formation characteristics are affected and changed by the injected waste material. Due to that fact, injection of waste into underground formations requires, along with standard requisite and obligatory monitoring, also constant monitoring and analysis of the formation characteristics and injection process. Injection of petroleum waste should be conducted according to recommended physical and rheological characteristics of waste due to feasibility specifications of injection facilities. The characteristics of waste to be injected are set by injection facility performances.

As regards technical aspects injection could be done through casing string or the injection tubing inside the long string casing either through perforations in the long string or in the open hole below the bottom of the long string. The annulus between injection tubing and casing string is filled with an inert, pressurized fluid and is sealed with packer preventing injected wastewater from backing up into the annulus. The completion of injection wells is shown in figure 1. The injection of the slurry is performed by injection facility that consists of a facility for preparation of the slurry, injection pumps and injection well (figure 2).

There are several advantages of injection technology over commonly used surface disposal of petroleum industry waste, including following:

- Less area intensive - the area that is occupied during injection activities is much smaller than the area occupied in case of surface disposal.

- Minimal chemical treatment of waste

- Negligible impact on the environment during normal work - the deep well injection is, at the moment, considered to be only permanent on- 
site disposal method available that can fully comply with zero discharge to the surface environment. By the injection cuttings are disposed in their native environment.

- Risk of environmental impact is at lowest rate compared to all know surface disposal methods (table 2).

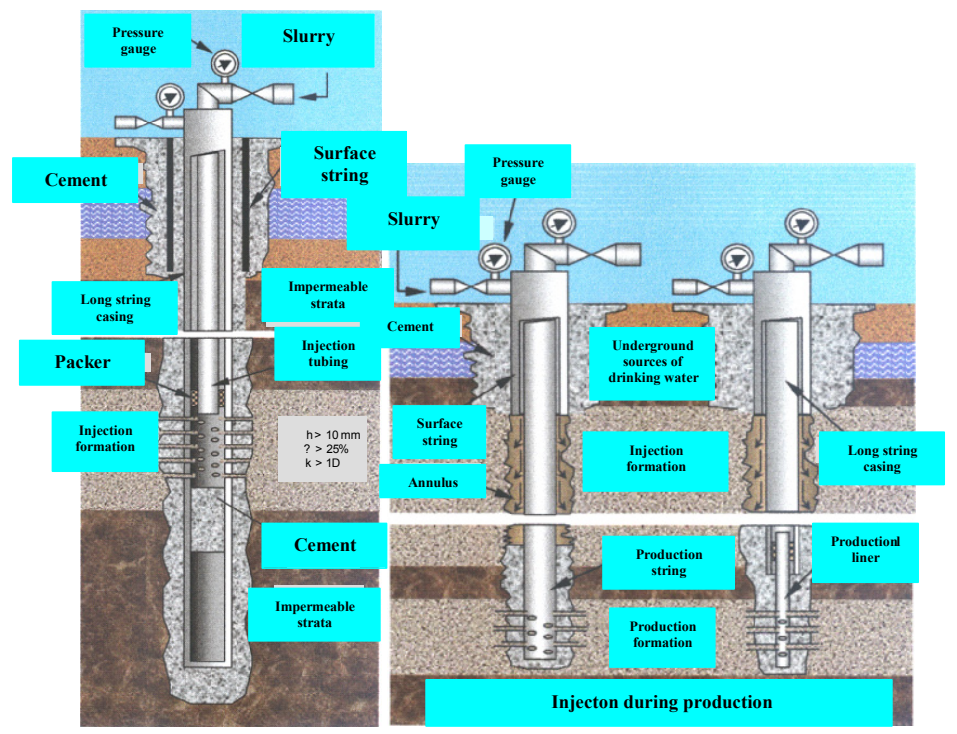

Figure 1: Completion of injection wells.

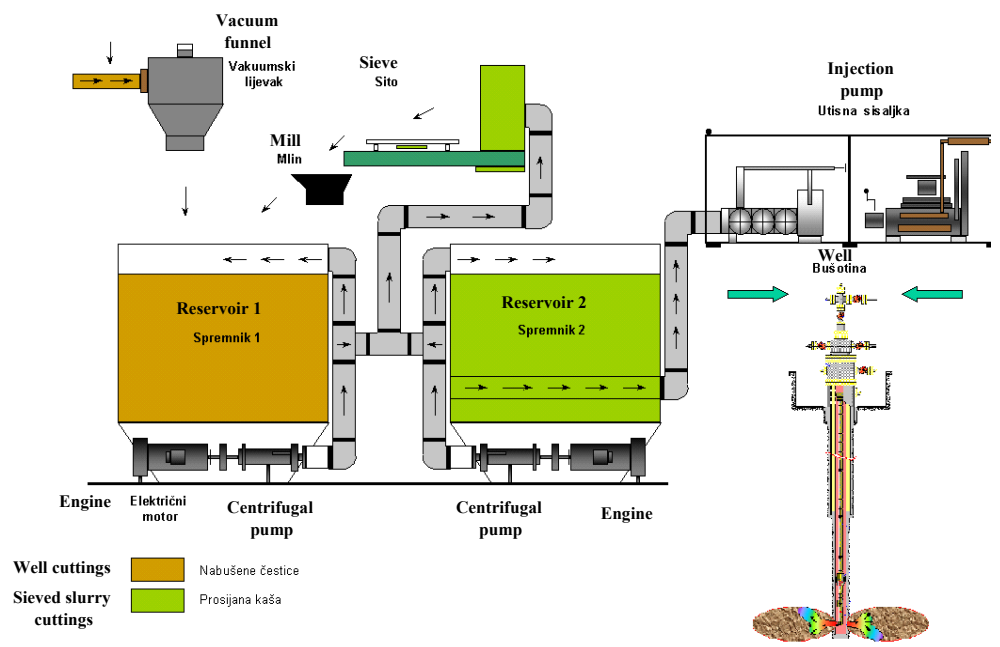

Figure 2: Mobile facility for petroleum industry waste injection. 
Table 2: $\quad$ Environmental risk of waste disposal methods.

\begin{tabular}{|c||c|}
\hline Methods of waste disposal & Environmental risk \\
\hline \hline Surface landfill & high \\
\hline Shallow burring on the spot & high \\
\hline Disposal into salt mines & low \\
\hline \hline Land Spreading & high \\
\hline Deep well injection & low \\
\hline Disposal into barrels on the spot & Very high \\
\hline
\end{tabular}

In addition to lower capital investments, reduced operating costs and minimal risk of environmental impact, the advantage of the injection technology, in comparison with the surface waste disposal, is a permanent disposal of waste into underground geological formation, from where the most part of the waste (water, $\mathrm{CO}_{2}$, cuttings, send, etc.) originated, by which the waste is permanently, safely and irretrievably removed from the immediate environment of the people (biosphere).

On the other hand, there are some factors that limit the applicability and effectiveness of petroleum waste injection like potential seismic activity, compatibleness of injected slurry with the existing fluid in the injection pore space and content and characteristics of the injected waste. In general, injection wells have to be located in seismically stable areas that are fee of transmissive fractures or faults through which injected fluids could vertically migrate.

The geological formation into which the waste is to be injected has to be sufficiently porous and permeable so that the waste can enter the rock formation without an excessive build up of pressure. The selection of injection wells and geological formations suitable for waste disposal is done based on tectonic and stratigraphic underground relations, physical characteristics and hydrogeological content of formation, physical and chemical characteristics and content of the waste, completion of the well and working regime during the field production. The formations suitable for disposal (injection) of waste are those isolated from their environment by impermeable cap and bed-rock, preventing uncontrolled dispersion and migration of waste out of boundaries of selected formation and pollution of underground water in shallower underground layers. Also, important factor of injection well selection represents economical warranty of injection activities. There are three critical factors that affect cost effectiveness of petroleum industry waste injection- volume of waste to be disposed, the availability of disposal infrastructure and the state regulatory system.

\section{Environmental impact of injection activities}

Since the injection activities are conducted in closed system, during normal working conditions, the impact on the environment is not expected. For ensuring a safe system, degree of safety during the injection activities is put on the highest 
level with the scope of additional environmental protection and safety measures. Prior to waste injection the environmental impact analysis of the injection activities should be done. Furthermore, it is necessary to analyze all other relevant characteristics of selected injection well, selected permeable formation, wellhead, content and characteristics of waste, well stability for injection purposes. Environmental protection measures and monitoring of injection activities should be conducted during the injection of waste into geological formation with high importance put on analysis of possible impacts of the injection on underground water.

For avoiding possible accidental situations the rules for construction, operating, monitoring, record keeping and reporting have been set.

Approved injection well, due to its construction and completion does not represent environmental threat during the non-injection period. However, during injection activities the environmental protection measures are conducted according to standard working procedures and set measures implemented in technical documentation of injection facility. After injection period the injection well should be stabilized.

Environmental protection measures, which are compulsory in Croatia, are operational safety measures, soil and underground water protection measures, fire and explosion protection measures and protection measures of the working area in accidental situations [1].

Along with environment protection measures taken, on injection well there should be constant monitoring and measurement of [1]:

- Static temperatures in specific time periods

- Spreading of waste injected into the formation (radioactive markers, oxygen activation method)

- $\quad$ Pressure measurement at wellhead and in annular space of the injection well

- $\quad$ Analysis and monitoring of pressure on nearby wells

- Analysis of integrity of the injection well

- Well logging

- Monitoring of chemical, physical and rheological characteristics of the injected waste

- Induced seismic and seismic monitoring

\section{Sequestration of $\mathrm{CO}_{2}$ by using injection technology}

Every year, human activities emit around 25 billion tons of $\mathrm{CO}_{2}$ into the atmosphere. About 2 to 3 billion tons of this annual output is absorbed by forests and another 7 billion tons is absorbed by the ocean [3]. Petroleum industry is one of GHG emission intensive industries. Due to increased global consciousness regarding climate change problems and increased emissions of greenhouse gases, carbon dioxide, as one of the wastes generated during hydrocarbon production, has gained a special place in petroleum industry's hierarchy of priorities. Beside direct $\mathrm{CO}_{2}$ and $\mathrm{CH}_{4}$ emissions with oil and gas production, petroleum industry is also characterized with high-energy intensity and final products with high 
emission potentials. The petroleum industry has been injecting carbon dioxide into geological formations for about 30 years. This injection has not been done in order to sequestrate $\mathrm{CO}_{2}$ but to displace or dissolve oil for increased/enhanced oil recovery (IOR or EOR). The pressure created by injection of carbon dioxide into the reservoir rock drives crude oil towards the production well. The injected $\mathrm{CO}_{2}$ emulsifies and partially dissolves the crude oil, which becomes more fluid and runs more easily to the production well.

Based on the Kyoto Protocol committed parties are obliged to decrease $\mathrm{CO}_{2}$ emissions for certain amount. Therefore, it is necessary to decrease industrial $\mathrm{CO}_{2}$ production and to manage produced $\mathrm{CO}_{2}$ in a safe manner. One of possible solutions for managing $\mathrm{CO}_{2}$ problem, not only in petroleum industry business, is its sequestration into underground formations by using injection technology. The first geological $\mathrm{CO}_{2}$ sequestration project was conducted by Statoil in the mid 1990 s at the Sleipner Vest field. From the beginning of the project nearly $1 \mathrm{Mt}$ $\mathrm{CO}_{2}$ /year is removed from natural gas and injected in to a water saturated sandstone formation deep under the North Sea [2]. Since over the past decade underground $\mathrm{CO}_{2}$ sequestration has emerged as one of the most promising methods for $\mathrm{CO}_{2}$ emission reduction, today there are several more commercial projects underway: the In Salah project in Algeria, the Gorgon Project in Australia, and the Snohvit Project in the Norwegian continental shelf. In addition to these, more are under development.

Key factor in process of disposal of $\mathrm{CO}_{2}$ represents adequate defining and choice of suitable geological formations. Today, four principle types of geological formations are considered to have significant potential for storing large amounts of $\mathrm{CO}_{2}$ [2]: active and depleted oil reservoirs, active and depleted gas reservoirs, saline formations and deep coal seams and coalbed methane formations.

Summary of worldwide storage capacity estimates is shown in table 2 .

Table 3: $\quad$ Summary of worldwide storage capacity estimates.

\begin{tabular}{|c|c|}
\hline Formation type & Capacity estimate $\left({\left.\mathrm{Gt} \mathrm{CO}_{2}\right)}\right.$ \\
\hline Depleted oil and gas reservoirs & $\sim 450$ \\
\hline Coalbed methane reservoirs & $60-150$ \\
\hline Salt - water saturated formations & $300-10,000$ \\
\hline
\end{tabular}

Carbon dioxide can be stored in these geological formations by four principle processes [2]:

- It can be trapped as gas or supercritical fluid in the pore zone of the injection formation

- It can dissolve into the fluid phase-solubility trapping

- It can become trapped a residual, non-wetting phase in the pore spaces of the formation

- It can react with the minerals and organic matter and become part of the solid mineral matrix. 
Injection of $\mathrm{CO}_{2}$ into deep underground geological formations, as a method to eliminate emissions of $\mathrm{CO}_{2}$, will not solve the problem of global warming itself, but it could dramatically reduce the amount of heat-trapping greenhouse gases released into the atmosphere.

\section{Implementation of injection technology in Croatia}

Like the others, so the Croatian national petroleum company, in last decade was also developing techniques and technologies to manage waste produced during oil and natural gas exploration and production by injection of this kind of waste into isolated, integral hydrodynamic underground geological formations by using deep well injection technology. During the intensive exploration and production of hydrocarbons in Croatia, nearly 5000 wells were drilled. Since, some of the drilled wells were wildcat and a great majority of rest was cut out of production during the time, there are a large number of unused wells. This fact enables Croatian petroleum industry to select wells suitable for safe and efficient petroleum industry waste disposal. Currently, petroleum industry waste is injected in only one well (Kal-6) on Kalinovac gas-condensate field located in the northern part of the country, in Koprivnica-Krizevac County. The selection of Kal- 6 well and its transformation from production into injection well has been done based on hidrogeological characteristics of reservoir, well completion and field production regime.

Pilot EOR project in Croatia started on mature oilfield Ivanic in 2001. The project was conducted in 5 phases that include successively injection of brine and $\mathrm{CO}_{2}$. The expected result of $\mathrm{CO}_{2}$ injection into mature oil field Ivanic in Croatia is $7-8 \%$ increase in oil production and prolonged production for at least 15 more years. Beside the potential opportunity of enhanced oil recovery from Ivanic and Zutica fields, important for domestic energy supply, the EOR project in Croatia also offers sustainable solution for the climate change problems and the challenges posed by the Kyoto Protocol commitments. By this project it is possible to sequestrate the 0,7 million tones per year of $\mathrm{CO}_{2}$ produced on gas field Molve, the biggest $\mathrm{CO}_{2}$ producer in Croatian petroleum industry and one of the biggest stationary emitters in the country.

\section{Conclusion}

By using the injection technology for disposal of waste generated during petroleum industry exploration and production activities into selected geological formations through technically suitable wells, the process of petroleum industry waste disposal will be, not only accelerated, but also conducted in a safe and efficient manner with total injection costs reduction. One of the main advantages of injection technology is permanent disposal of waste deep beneath the surface with "zero" pollution of the environment. The formations suitable for disposal (injection) of waste are those isolated from their environment by impermeable 
cap and bed-rock, preventing uncontrolled dispersion and migration of waste out of boundaries of selected formation and pollution of underground water in shallower underground layers.

Over the past decade underground $\mathrm{CO}_{2}$ sequestration has emerged as one of the most promising methods for $\mathrm{CO}_{2}$ emission reduction. Injection of $\mathrm{CO}_{2}$ into deep underground geological formations, will not solve the problem of global warming itself, but it could dramatically reduce the amount of heat-trapping greenhouse gases released into the atmosphere.

\section{References}

[1] Group of authors, Environmental Impact Study for the Petroleum Waste Injection in Osjecko- baranjska County in the Republic of Croatia, Faculty of Mining, Geology \& Petroleum Engineering, Zagreb, 2003

[2] Benson, S. M., Overview of Geologic Storage of $\mathrm{CO}_{2}$, Carbon Dioxide Capture for Storage in Deep Geologic Formation, Vol. 2, pp. 665-670, 2005

[3] Lawrence National Laboratory, Science and Technology Review, pp. 2022, 2005

[4] Environmental Protection Agency, Statement of Basis and Purpose of Underground Injection Control Regulations, 1980

[5] Environmental Protection Agency, Class I Underground Injection Control Program: Study of the Risks Associated with Class I Underground Injection Wells, 2001

[6] Environmental Protection Agency, Code of Federal Regulations Protection of Environment 40, parts 139-149, 1998

[7] Apps, J. A., Tsang, C., Deep Injection Disposal of Hazardous and Industrial Waste, 1996

[8] www.ina.hr 